\title{
Research on a Pitching Movement Mode of A Water Surface Monitoring Catamaran Unmanned Craft
}

\author{
Yan Shi , Baojiang Wang, Songling Yang, Shasha Gao, Tianming Hu
}

\begin{abstract}
In this paper,a water surface monitoring catamaran unmanned craft was taken as the research object,and a series of static water pitch attenuation tests were carried out under different drafts and different initial pitch angles.According to the principle of dynamic balance in the pitching motion, the identification mathematical models of four pitch motion modes are established by changing the composition of restoring torque.Based on the theory of system identification and the idea of genetic algorithm, the software of system identification is programmed with $\mathrm{C \#}$ language.A better mathematical model and equation of motion are identified through the identification of test data.Using the equation of motion for forecasting,the relative errors between the predicted values and the experimental values are in good agreement, which proves the feasibility and reliability of the system identification method.Finally, the processed data is analyzed and the relevant hydrodynamic coefficient curve is given. The variation law of each moment coefficient affecting the pitching motion with the draft and the initial pitch angle is analyzed.The ship's pitching motion is characterized by nonlinearity. Under the disturbance of navigation conditions and environment, its dynamic characteristics will produce uncertainty. If it can be accurately and effectively predict the movement of the ship in the next few seconds, it will have a great impact on navigation decisions. The research in this paper can predict the future navigation parameters and motion posture of unmanned boats.At the same time, it provides a reference for studying the wave resistance of such boats and the optimized design of subsequent boats.Provide technical support for improving the wave resistance of unmanned boats, and propose corresponding improvement methods.
\end{abstract}

Index Terms - catamaran unmanned craft, pitch motion mode, system identification, ship model test

\section{INTRODUCTION}

The surface unmanned boat is a tool for searching and detecting marine information. In recent years, it has been highly valued by various maritime powers. With the improvement of the economic level, the ability of ocean transportation has become more and more important for the development of countries, and the important position of the research on the model of ship motion has become more prominent[3].Since the unmanned boat needs to overcome the external disturbances that are not known beforehand to complete the task independently, this requires the unmanned boat to have good maneuverability and seakeeping resistance, and the forecast becomes a prerequisite that must be paid attention to at the beginning of the design.

It is weaker in terms of seakeeping and airworthiness than other aspects of unmanned boats, limiting its maximum

Yan Shi , Baojiang Wang, Songling Yang, Shasha Gao, Tianming Hu, School of Naval Architecture \& Ocean Engineering , Jiangsu University of Science and Technology, Zhenjiang, Jiangsu, China functionality [1].Ship model experiment is an important tool to study the ship's sea wave resistance.Through the ship model experiment, the frequency response functions of roll, pitch and heave motion can be determined, and the motion statistics of the actual ship under a given wave level can be predicted.In the analysis of ship model experiments, the application of system identification method has been used for a long time[7].In recent years, identification techniques have been continually cited in the identification of hydrodynamic derivatives of ship maneuvering movements, the establishment of mathematical models of maneuvering movements, and made great progress.At this stage, there are two main methods for analyzing the hydrodynamic coefficients of the ship model pitch, one is theoretical modeling analysis, and the other is analysis using the identification program.The use of theoretical modeling to determine the hydrodynamic coefficient is very complicated and the workload is large. In particular, it is more difficult to calculate the coupling between the pitch and the heave when the pitching motion is performed.Therefore, most of the experimental data is analyzed by the identification program, and finally combined with the optimization algorithm to obtain the optimal identification result.At present, most of the research at home and abroad mainly focuses on the rolling motion of the wave resistance, and the pitching research is rare [2].Therefore, it is very meaningful to study the pitch motion mode of unmanned boats.In this paper, a water surface monitoring catamaran unmanned craft is taken as the research object, and its pitching motion mode is analyzed by ship model experiment and system identification method.

\section{STATIC WATER PITCHING TEST}

\section{A. Test Model:}

This pitch test used a water surface monitoring catamaran unmanned craft. Based on a type of slender old-fashioned frigate as a mother ship, and comprehensive optimization to obtain the optimal main scale as shown in Table1:

Table 1 Optimization results of the main scale of the two-body unmanned boat

\begin{tabular}{cllll}
\hline Number & Design variable & Symbol & Value & Unit \\
\hline 1 & Length & $\mathrm{L}$ & 1.472 & $\mathrm{~m}$ \\
2 & Sheet width & $\mathrm{B}$ & 0.13 & $\mathrm{~m}$ \\
3 & Slice spacing & $\mathrm{C}$ & 0.26 & $\mathrm{~m}$ \\
4 & Depth & $\mathrm{D}$ & 0.0788 & $\mathrm{~m}$ \\
5 & Draft & $\mathrm{d}$ & 0.0463 & $\mathrm{~m}$ \\
6 & Block coefficient & $\mathrm{Cb}$ & 0.552 & \\
7 & Waterplane coefficient & $\mathrm{Cw}$ & 0.770 & \\
8 & Midship section coefficient & $\mathrm{Cm}$ & 0.889 & \\
9 & Velocity & $\mathrm{V}$ & 5 & $\mathrm{kn}$ \\
10 & Displacement & $\Delta$ & 10 & $\mathrm{~kg}$ \\
\hline
\end{tabular}


The three-dimensional model of the ship model is shown in Figure 1:

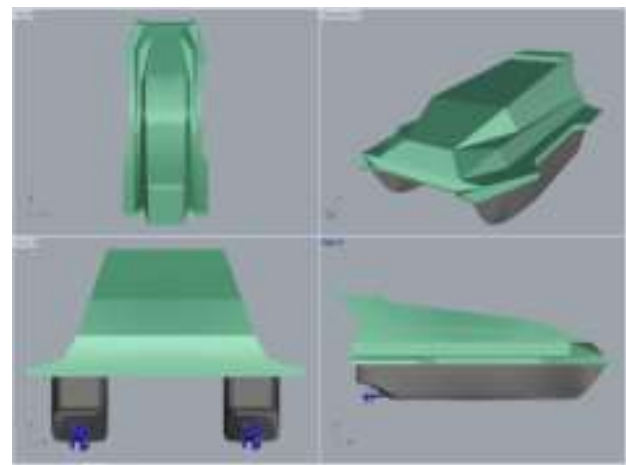

Figure $13 \mathrm{D}$ model of the ship model

\section{1) B. Test Equipment}

Test preparation: test ship model, MTi-G inertial measurement instrument, data transmission line, shore computer, ballast, electronic scale,double-sided tape[10].

The MTi-G is a miniature inertial measurement system with integrated GPS signals. It can output three-axis acceleration, three-axis angular velocity, and three-axis attitude angle (pitch angle / roll angle / heading angle). Built-in high-precision anti-vibration gyroscope chip $\left(10^{\circ} / \mathrm{h}\right)$, it can output three-axis attitude angle with high precision in vibration environment and non-uniform magnetic field environment.

Use $0.01 \mathrm{~s}$ as the recording period of the instrument, that is, every 0.01 s to collect a set of data, this set of data includes 3 linear degrees of freedom acceleration, 3 rotational degrees of angular velocity, local X, Y, Z Three-axis real-time magnetic field strength. The instrument is connected to a computer and can record motion data in real- time.

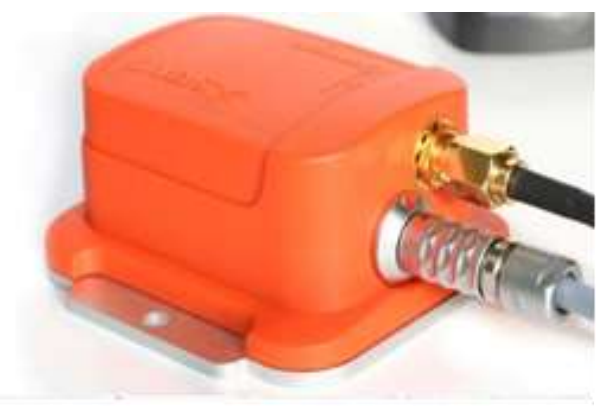

Figure 2 MTi-G Micro AHRS Inertial Measurement System

\section{Pitch Test Plan}

The test was carried out in the wave pool of Jiangsu University of Science and Technology, and each of the three different draught of 0.9 times, standard and 1.1 times was used. The initial pitch angles were $1^{\circ}, 3^{\circ}, 5^{\circ}, 7^{\circ}$ and a total of 12 sets of pitch tests. The specific test process is as follows[11]:

(1)The center of gravity and the no-load weight of the boat model were measured before the test;

(2)Placed the MTi-G inertial measuring instrument horizontally at the center of gravity of the ship model and connected the devices with data cables;

(3)Placed the ship model in the pool, passed the load and adjusted the ballast position to make the ship model in a positive floating state, so that the draft was at the design waterline;

(4)When the ship model was in the positive floating state, the pitch angle was read by software, and through adjusted the horizontal position of the MTi-G, the initial pitch angle displayed on the software is between $-0.2^{\circ}$ and $0.2^{\circ}$;

(5)Under the standard draught condition, manually gave the ship model a required pitch angle, clicked on the recorded data, and released the ship model. When the ship model returned to the positive floating state, stopped the data acquisition and saved the test data;

(6)Repeated steps 4)-5) for a total of 4 initial pitch angles of $1^{\circ}, 3^{\circ}, 5^{\circ}, 7^{\circ}$;

(7)The draught test of 1.1 times and 0.9 times was carried out by adding or reducing ballast.

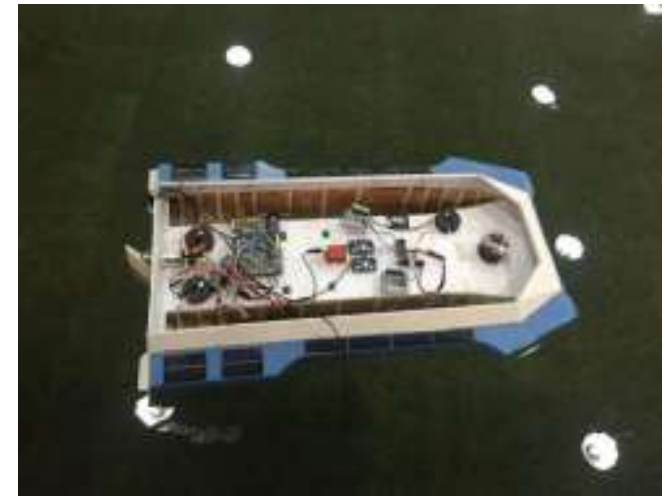

Figure 3 Two-body unmanned boat static water pitch attenuation test

\section{SYSTEM IDENTIFICATION BASED ON GENETIC ALGORITHM}

\section{A. System Identification}

System identification is a branch of modern control theory. Based on the known or measured system input and output data, the system identification determines a model equivalent to the measured system from a given set of model[4]. The three elements of system identification are: data, model class, and equivalence criterion. Data is the basis of identification, which refers to the input data and output data of the system process. The model class is the range of finding the model when identifying, referring to various types. A known set of system process models; the equivalence criterion is the goal of identification optimization, which refers to the identification criteria of system behavior similarity and system utility equivalence[15]. The essence of identification is to select a model from a set of known model classes according to certain criteria, so that it can best fit the dynamic or static characteristics of the actual system reflected by the input and output observation data of the system. The purpose of identification is to grasp the laws of things, to recognize things, and to use the results of identification to solve practical problems[8].

\section{B. Identification of mathematical models}

According to the hydrostatic moment balance formula, we transform the terms of the restored moment in the pitch equation in the form of quadratic, quadratic, cubic and sine, respectively, to find the pitch equation that fits the ship model in this paper [5]. 
The identification formula 1 is that when the ship is tilted to a small angle, the damping torque is nonlinear, and the restoring moment is linear, the model equation is[13]:

$$
\begin{aligned}
& \ddot{\psi}+2 \frac{M}{I_{\mathrm{y}}} \ddot{\psi}+\frac{V}{I_{\mathrm{y}}}|\dot{\psi}| \dot{\psi} \\
& +\frac{\mathrm{y}}{I_{\mathrm{y}}} \ddot{\psi}^{3}+\frac{D \mathbf{D}}{I_{\mathrm{y}}} \boldsymbol{\psi}=\mathrm{O}
\end{aligned}
$$

The identification formula 2 is that the damping torque is nonlinear, and when the restoring moment is a linear plus square term, the model equation is:

$$
\begin{aligned}
& \ddot{\psi}+2 \frac{M}{I_{\mathrm{y}}} \dot{\psi}+\frac{V}{I_{\mathrm{y}}}|\dot{\psi}| \dot{\psi}+ \\
& \frac{\mathrm{y}^{3}}{I_{\mathrm{y}}}+\frac{C_{2}}{I_{\mathrm{y}}} \psi^{2}+\frac{C_{3}}{I_{\mathrm{y}}} \psi=0
\end{aligned}
$$

The identification formula 3 is that the damping torque is nonlinear, and the restoring moment is a linear plus square term plus three terms, the model equation is:

$$
\begin{aligned}
& \ddot{\psi}+2 \frac{M}{I_{\mathrm{y}}} \dot{\psi}+\frac{V}{I_{\mathrm{y}}}|\dot{\psi}| \dot{\psi}+\frac{\mathrm{y}}{I_{\mathrm{y}}} \dot{\boldsymbol{\psi}}^{3} \\
& +\frac{C_{1}}{I_{\mathrm{y}}} \psi^{3}+\frac{C_{2}}{I_{\mathrm{y}}} \psi^{2}+\frac{C_{3}}{I_{\mathrm{y}}} \psi=0
\end{aligned}
$$

The identification equation 4 is that the damping torque is nonlinear and the restoring moment is a linear plus square of the sine value plus three times. The model equation is:

$$
\begin{aligned}
& \ddot{\psi}+2 \frac{M}{I_{\mathrm{y}}} \dot{\psi}+\frac{V}{I_{\mathrm{y}}}|\dot{\psi}| \dot{\psi}+\frac{\mathrm{y}}{I_{\mathrm{y}}} \dot{\psi}^{3}+ \\
& \frac{C_{1}}{I_{\mathrm{y}}}(\sin \psi)^{3}+\frac{C_{2}}{I_{\mathrm{y}}}(\sin \psi)^{2}+ \\
& \frac{C_{3}}{I_{\mathrm{y}}} \sin \psi=0
\end{aligned}
$$

Among the above four identification formulas: $I_{\mathrm{y}}-$ the total moment of inertia of the hull pitch; ${ }^{\psi}$ - pitch angle; $\dot{\psi}$ - pitch angular velocity; $\ddot{\psi}$ - pitch angular acceleration; M- pitch linear damping torque coefficient; $\mathrm{V}$ and $\mathrm{y}$ - pitch nonlinear damping Moment coefficient; $C_{1}$ - linear recovery moment coefficient; $C_{2}$ - square term recovery moment coefficient; $C_{3}$ - cubic square recovery moment coefficient;

Among the four identification models, the error estimation criterion at the $\mathrm{K}+1$ th moment is obtained by measuring the angle of the experiment $\mathrm{K}$ :

$$
\varepsilon_{k+1}=\dot{\psi}_{k+1}^{\prime}-\dot{\psi}_{k+1}
$$

In the formula: $\dot{\psi}^{\prime}{ }_{K+1}$ is the measured value of the angular velocity at time $\mathrm{k}+1, \dot{\psi}_{K+1}$ is the value obtained by the identification result.

The objective function of the pitch identification model is established according to the error estimation criterion as follows. In the optimization calculation, the smaller the objective function value that needs to be recognized by the pitch, the better, and the smaller $\mathrm{F}(\mathrm{x})$, the better the equation fitting effect.

$$
F(x)=\sqrt{1 / M \sum_{k=1}^{M}\left(\dot{\psi}_{K+1}^{\prime}-\dot{\psi}_{K+1}\right)^{2}}
$$

Select the design variable: $I_{\mathrm{y}}, M, V, \mathrm{y}, C_{1}, C_{2}, C_{3}$.The range of design variables is shown in Table 2.

Table 2 Range of Design Variables

\begin{tabular}{ll}
\hline Project & Ranges \\
\hline Total moment of inertia $I_{\mathrm{y}}$ & $0 \sim 0.1$ \\
Pitch linear damping moment coefficient M & $0 \sim 1$ \\
Pitch nonlinear damping moment coefficient V & $0 \sim 1$ \\
Pitch nonlinear damping moment coefficient y & $0 \sim 10$ \\
Cubic recovery moment coefficient $C_{1}$ & $0 \sim 10$ \\
Quadratic recovery moment coefficient $C_{2}$ & $0 \sim 10$ \\
Linear recovery moment coefficient $C_{3}$ & $0 \sim 10$ \\
\hline
\end{tabular}

\section{ANALYSIS OF TEST RESULTS}

\section{A. Analysis of the results of the pitch test}

The static water vertical shaking test of the catamaran unmanned craft was completed. During the test, each initial pitch angle was tested three times, and the best set of test data was selected as the effective data. Due to the human measurement factor, there is a certain error in the test. Figure 4 shows the initial pitch angle of $3^{\circ}$, the draught is 0.9 times the design draught, the design draught, and the 1.1 times the design draught. The composite law of the pitch angular velocity attenuation from the figure proves the vertical Shake test data is available.

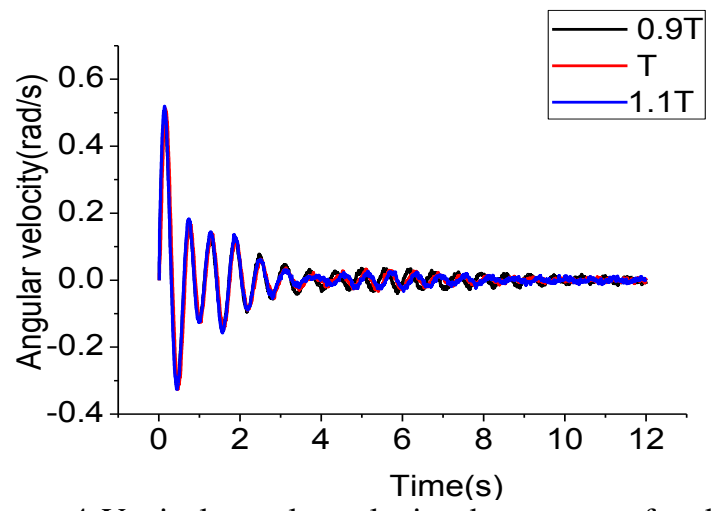

Figure 4 Vertical angular velocity decay curve for different drafts with a pitch angle of $3^{\circ}$ 
As shown in Figure 4, when the three groups draught and the initial pitch angle is $3^{\circ}$, the peak of the pitch angular velocity increases with the increase of the draft, the pitch period decreases, and the displacement is 1.1 times when the draft is designed. The time that the model reaches a steady state is the shortest.

\section{B. Identification calculation scheme}

Mathematical model: Equations 1-4.

Scheme design: identification optimization algorithm selection genetic algorithm, growth mechanism [6].

The basic parameters of the genetic algorithm are set: population size 200 , crossover probability 0.8 , mutation probability 0.15 , calculation number 2000 generation, genetic factor 0.5 , and evolution weight 0.5 [9].

The test data selects three drafts of the ship model in the paper, and the corresponding pitch angles are $1^{\circ}, 3^{\circ}, 5^{\circ}, 7^{\circ}$, and a total of 12 sets of data are identified. The value of the identification objective function is shown in Table 3:

Table 3 Identification Objective Function Calculation Results

\begin{tabular}{|c|c|c|c|c|c|}
\hline & $\begin{array}{l}\text { Mathema } \\
\text { tical } \\
\text { model }\end{array}$ & formula 1 & formula 2 & formula 3 & formula 4 \\
\hline \multirow{4}{*}{$\begin{array}{l}0.9 \text { times } \\
\text { Design } \\
\text { draught }\end{array}$} & $\begin{array}{l}\text { Pitch } \\
{\text { angle } 1^{\circ}}^{\circ}\end{array}$ & $\begin{array}{l}0.00856607 \\
3\end{array}$ & $\begin{array}{l}0.0085661 \\
27\end{array}$ & $\begin{array}{l}0.0085660 \\
20\end{array}$ & $\begin{array}{l}0.008566 \\
076\end{array}$ \\
\hline & $\begin{array}{l}\text { Pitch } \\
\text { angle } 3^{\circ}\end{array}$ & $\begin{array}{l}0.00851957 \\
9\end{array}$ & $\begin{array}{l}0.0085199 \\
85\end{array}$ & $\begin{array}{l}0.0085200 \\
06\end{array}$ & $\begin{array}{l}0.008519 \\
247\end{array}$ \\
\hline & $\begin{array}{l}\text { Pitch } \\
\text { angle5 }\end{array}$ & $\begin{array}{l}0.01034633 \\
1\end{array}$ & $\begin{array}{l}0.0103463 \\
99\end{array}$ & $\begin{array}{l}0.0103396 \\
93\end{array}$ & $\begin{array}{l}0.010339 \\
507\end{array}$ \\
\hline & $\begin{array}{l}\text { Pitch } \\
\text { angle } 7^{\circ}\end{array}$ & $\begin{array}{l}0.01101537 \\
3\end{array}$ & $\begin{array}{l}0.0110160 \\
87\end{array}$ & $\begin{array}{l}0.0110063 \\
90\end{array}$ & $\begin{array}{l}0.011007 \\
653\end{array}$ \\
\hline \multirow{4}{*}{$\begin{array}{l}\text { Design } \\
\text { draught }\end{array}$} & $\begin{array}{l}\text { Pitch } \\
\text { angle } 1^{\circ}\end{array}$ & $\begin{array}{l}0.00996629 \\
7\end{array}$ & $\begin{array}{l}0.0099657 \\
86\end{array}$ & $\begin{array}{l}0.0099654 \\
72\end{array}$ & $\begin{array}{l}0.009965 \\
371\end{array}$ \\
\hline & $\begin{array}{l}\text { Pitch } \\
\text { angle } 3^{\circ}\end{array}$ & $\begin{array}{l}0.00872793 \\
3\end{array}$ & $\begin{array}{l}0.0087280 \\
56\end{array}$ & $\begin{array}{l}0.0087281 \\
45\end{array}$ & $\begin{array}{l}0.008728 \\
585\end{array}$ \\
\hline & $\begin{array}{l}\text { Pitch } \\
\text { angle } 5^{\circ}\end{array}$ & $\begin{array}{l}0.01053142 \\
86\end{array}$ & $\begin{array}{l}0.0105331 \\
35\end{array}$ & $\begin{array}{l}0.0105304 \\
92\end{array}$ & $\begin{array}{l}0.010531 \\
444\end{array}$ \\
\hline & $\begin{array}{l}\text { Pitch } \\
\text { angle } 7^{\circ}\end{array}$ & $\begin{array}{l}0.01031751 \\
5\end{array}$ & $\begin{array}{l}0.0103176 \\
29\end{array}$ & $\begin{array}{l}0.0103207 \\
01\end{array}$ & $\begin{array}{l}0.010319 \\
078\end{array}$ \\
\hline \multirow{4}{*}{$\begin{array}{l}\text { 1.1times } \\
\text { Design } \\
\text { draught }\end{array}$} & $\begin{array}{l}\text { Pitch } \\
\text { angle } 1^{\circ}\end{array}$ & $\begin{array}{l}0.00943597 \\
9\end{array}$ & $\begin{array}{l}0.0094290 \\
24\end{array}$ & $\begin{array}{l}0.0094284 \\
61\end{array}$ & $\begin{array}{l}0.009428 \\
980\end{array}$ \\
\hline & $\begin{array}{l}\text { Pitch } \\
\text { angle } 3^{\circ}\end{array}$ & $\begin{array}{l}0.00934602 \\
1\end{array}$ & $\begin{array}{l}0.0093468 \\
00\end{array}$ & $\begin{array}{l}0.0093447 \\
78\end{array}$ & $\begin{array}{l}0.009345 \\
589\end{array}$ \\
\hline & $\begin{array}{l}\text { Pitch } \\
\text { angle5 }\end{array}$ & $\begin{array}{l}0.00969239 \\
6\end{array}$ & $\begin{array}{l}0.0096930 \\
72\end{array}$ & $\begin{array}{l}0.0096900 \\
59\end{array}$ & $\begin{array}{l}0.009691 \\
330\end{array}$ \\
\hline & $\begin{array}{l}\text { Pitch } \\
\text { angle } 7^{\circ}\end{array}$ & $\begin{array}{l}0.01305825 \\
7\end{array}$ & $\begin{array}{l}0.0130598 \\
19\end{array}$ & $\begin{array}{l}0.0130410 \\
68\end{array}$ & $\begin{array}{l}0.013050 \\
134\end{array}$ \\
\hline
\end{tabular}

Comparing 0.9 times design draught, design draught and 1.1 times three draught, the four pitch identification models were used to identify, according to the size of the objective function, the identification model most suitable for the catamaran unmanned craft was selected.

It can be seen from Table 3 that under the three kinds of draught, the value of Formula 4 of the objective function of the identification calculation is the smallest, indicating that the formula IV has the best fitting effect. Taking 0.9 times design draught and initial pitch angle of $3^{\circ}$ as an example, the target function value after identification is 0.00805119 . The values of each design variable are shown in Table 4 :
Table 4 Equation 4 identifies the optimization values of each design variable

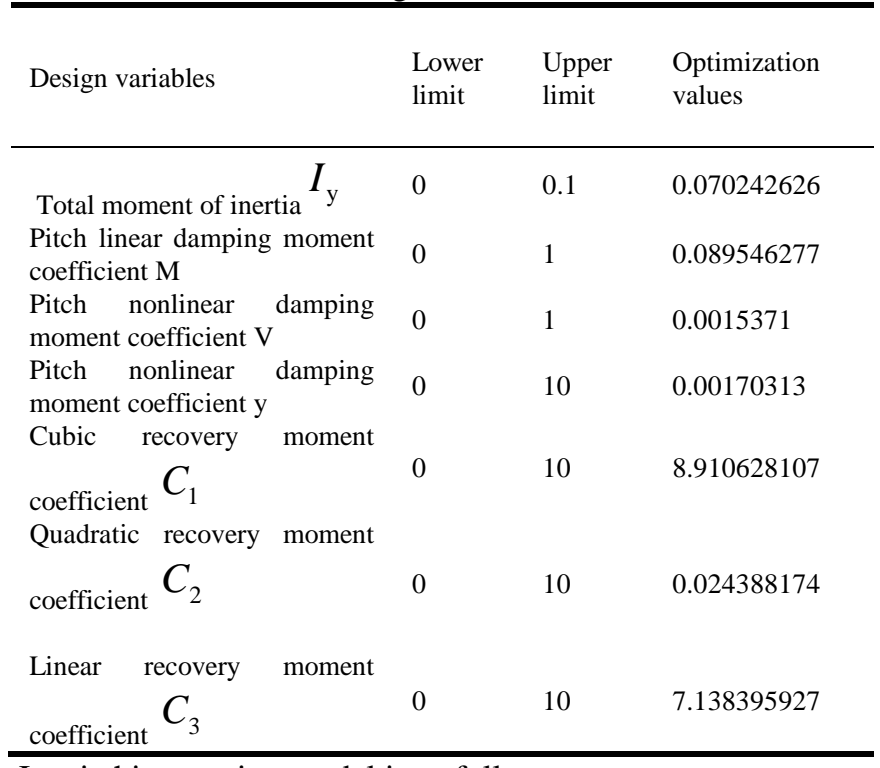

Its pitching motion model is as follows:

$\ddot{\psi}+2.54963 \ddot{\psi}+$

$0.0218 \$ \dot{\psi} \mid \dot{\psi}+$

- 3

$0.024246 \%$

$+126.8550 \% \sin \psi)^{3}+$

$0.347199 \sin \psi)^{2}+$

$101.62484 \sin \psi=\mathrm{O}$

In order to analyze the error between the experimental value and the fitted value, the angular velocity test value of the 0.9 times design draught and the initial pitch angle of $3^{\circ}$ and the fitting value identified by the formula 4 are placed in the same coordinate system, as shown in the figure 5 shows:

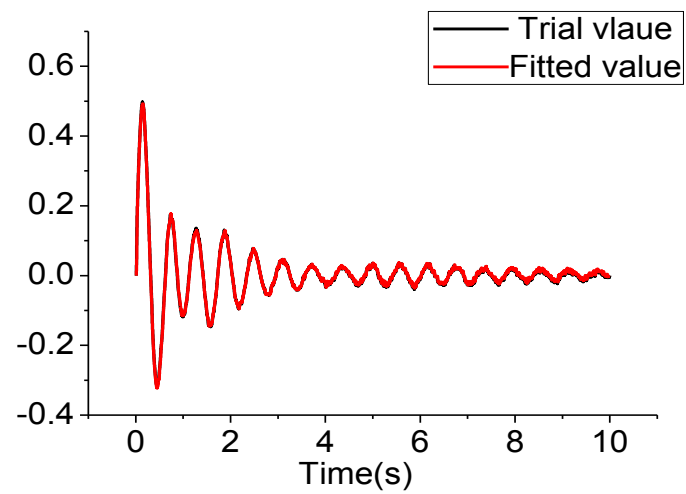

Figure 5 Test angular velocity and identification angular velocity fitting curve

It can be seen from the above figure that the test angular velocity and the identification angular velocity have a good fitting effect, which can prove the reliability of the identification software compiled in this paper. Therefore, the identification software can predict the pitch angular velocity at the next moment.

Through the identification calculation of 12 sets of pitch test data, the total moment of inertia of the ship model pitch, the longitudinal linear damping torque coefficient $\mathrm{M}$, the square damping torque coefficient $\mathrm{V}$, the cubic damping torque coefficient $y$ and each of each case are obtained. Restore the 
torque factor[12]. Among them, the variation curve of each design variable with the initial pitch angle under three kinds of draught is shown in Figure 6-8:

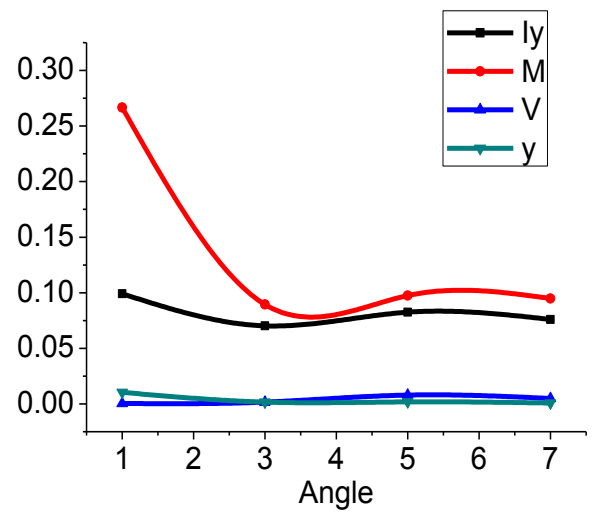

(a)

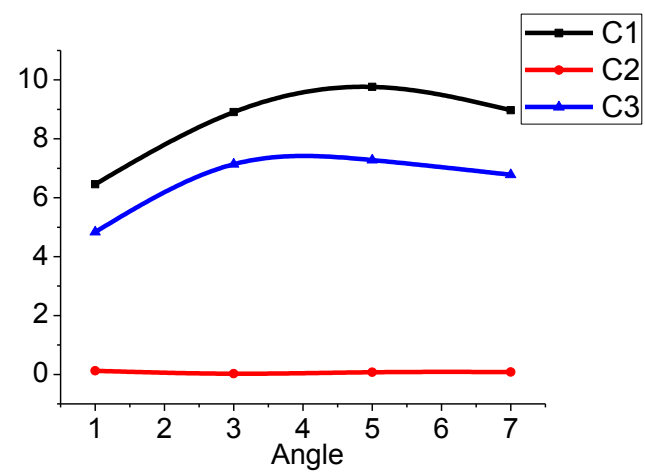

(b)

Figure 60.9 times the design of draught torque coefficient with the initial pitch angle

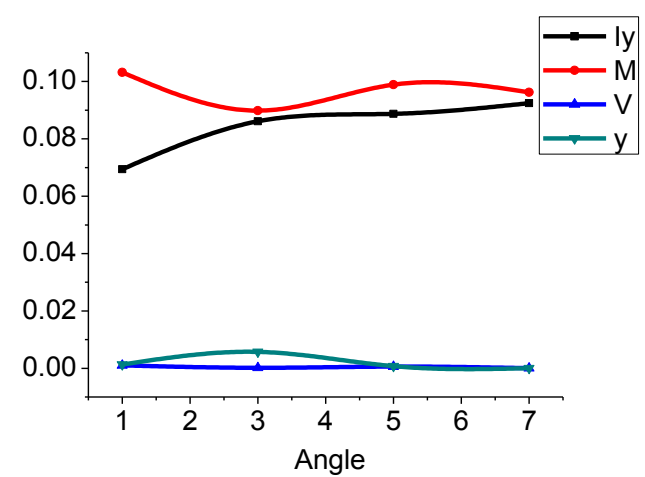

(a)

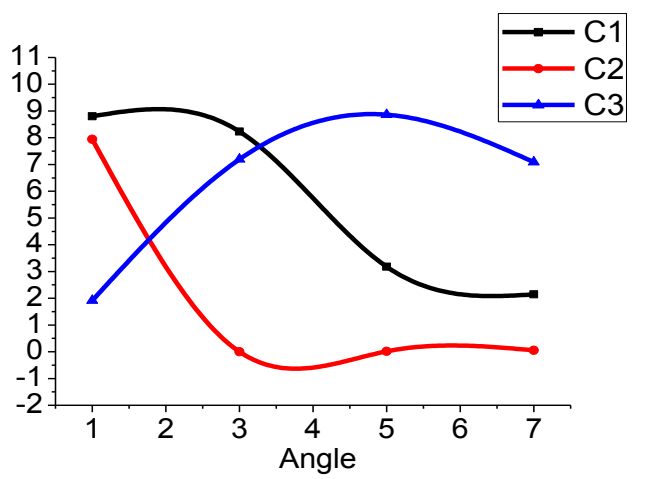

(b)

Figure 7 The curve of each moment coefficient under standard draught with the initial pitch angle

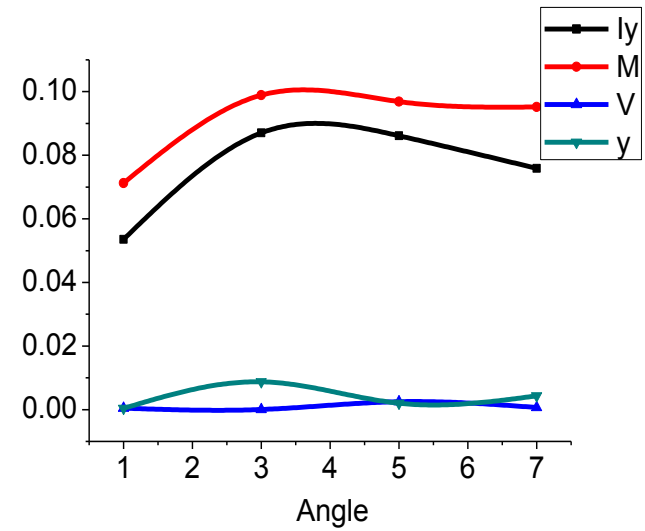

(a)

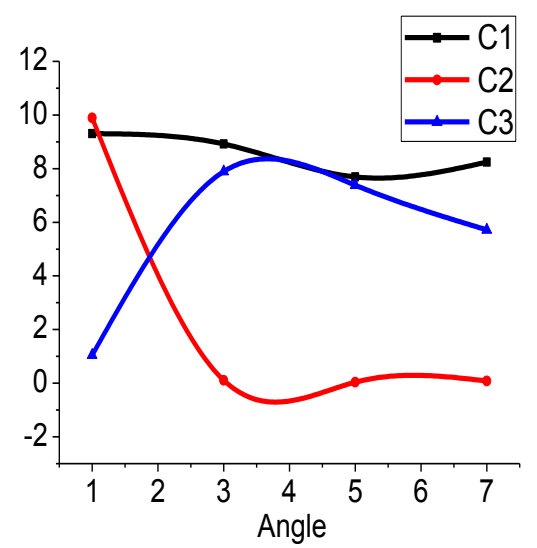

(b)

Figure 81.1 times the design of draught torque coefficient with the initial pitch angle

As can be seen from Figure 6-8, the values of the torque coefficients will change with the change of draught and initial pitch angle.

It can be seen from Figure 6-8 that the values of the torque coefficients will change with the change of the draft and the initial pitch angle. As the draft increases, the total moment of inertia of the hull and the linear damping $M$ will decrease. Trend; the value of the squared damping coefficient $\mathrm{V}$ is almost close to zero and remains stable. The cubic damping is larger at $3^{\circ}$ and the other angles are almost close to 0 ; in the case of standard draft and 1.1 times draft, the squared recovery moment coefficient decreases greatly with the increase of the pitch angle and then remains stable; Under the water, as the pitch angle increases, the linear recovery torque shows a tendency to increase first and then decrease.

Observing (a) of Figure 6-8, it can be seen that as the pitch angle increases, the linear damping coefficient $\mathrm{M}$ has the largest variation, followed by the hull pitch total moment of inertia. Explain that both have a great influence on the pitching motion. The square damping moment coefficient $\mathrm{V}$ and the cubic damping moment coefficient y change little with the increase of the pitch angle, and remain stable. It shows the influence of the nonlinear damping $\mathrm{V}$ and $\mathrm{M}$ on the pitch motion of the boat model during the pitching motion Smaller. Observing (b) of Figure 6-8, it can be seen that with the increase of the pitch angle, the linear recovery torque has a larger amplitude, which increases first and then decreases, and has a pitch angle of about $4^{\circ}$. The maximum value; the quadratic recovery torque is stable at 0.9 times the draught, but it is abnormal when it is draught, and it is greatly reduced 
and then remains stable. The cubic recovery torque is in a large and unstable state. It shows that the recovery moment coefficient has a considerable influence on the pitching motion.

\section{CONCLUSION}

The ship's pitching motion is characterized by nonlinearity. Under the disturbance of navigation conditions and environment, its dynamic characteristics will produce uncertainty. If it can be accurately and effectively predict the movement of the ship in the next few seconds, it will have a great impact on navigation decisions.

In this paper, the model test and system identification method are used to study the hydrostatic pitch attenuation motion mode of the surface monitoring catamaran unmanned craft.The mathematical model of hydrostatic pitch, which is most suitable for the ship model under the 12 working conditions, and the variation law of each moment coefficient with the pitch angle of three different draught are obtained by the identification program.At the same time, the correctness of the system identification software is verified[14]. The research shows that the system identification software can predict the future navigation parameters and motion posture of the unmanned boat, and provide reference for further study of the catamaran pitch motion.

\section{REFERENCE}

[1] Yan Minghao, Zhang Gongzi, Yang Songlin, Zhang Sheng. Research on Nonlinear Pitching Motion Mode of Multi-Navigation Unmanned Boat[Z]. The 20th China International High Performance Ship Academic Conference and China International Yacht Design and Construction Technology Forum, April 10-11, 2015.

[2] Zhang Wei, Ma Jianhong. Analysis of the model of pitch motion pattern recognition based on genetic algorithm [J].Ship Science and Technology, Vol. 37, No. 11, November 2015.

[3] Cui Ruonan. Parameter identification of ship pitch and heave motion based on improved particle swarm optimization [D]. Harbin Engineering University, 2015.

[4] Li Yongtao. Research on parameter identification method for surface unmanned boats [D]. Harbin Engineering University, 2015.

[5] Li Jun. Research on a motion pattern recognition system for surface unmanned boats [D]. Jiangsu University of Science and Technology, 2016

[6] Yan Minghong.Analysis and research of genetic algorithm applied in system identification[J].Research results,2016,11.

[7] ZHU Feng, YANG Songlin. Preliminary Study on Identification Method of Pitch and Heave Motion Mode System of Composite Trimaran[J].CCDC,2014,26th

[8] Zhu F, Yang S. Primary research on the system identification method of pitching and heave motion of composite trimaran[C]//Control and Decision Conference. IEEE, 2014:1172-1176.

[9] Valarmathi K, Devaraj D, Radhakrishnan T K. Real-coded genetic algorithm for system identification and controller tuning[J]. Applied Mathematical Modelling, 2009, 33(8):3392-3401.

[10] Wang G S, Huang F. APPLICATION OF GENETIC ALGORITHM AND GAUSS-NEWTON METHOD TO SYSTEM IDENTIFICATION[C]// Advanced Nondestructive Evaluation II. 2015:475-480.

[11] D Dumitru,Numerical investigation of a two - degrees - of - freedom ship model for pitch - roll motion [C] ,IOP Conference Series: 10.1088/1757-899X/145/8/082007,2016.

[12] Li Wei.Based on the nonlinear dynamic response characteristics of wave-induced and vortex-induced sloshing-rolling-pitching of a Spar platform [D].Tianjin University, 2017.

[13] Sun Xiaoshuai, Yao Chaobang, Ye Qing. Numerical and Experimental Study on Rolling Damping Characteristics of Small
Waterplane Catamaran[J]. Journal of National University of Defense Technology, 2017(6).

[14] Liu S, Papanikolaou A. Prediction of parametric rolling of ships in single frequency regular and triple frequency group waves[J]. Ocean Engineering, 2016, 120:274-280.

[15] Zhang Heng, Li Jide, Zhao Xiaodong. Solving nonlinear motion response of ship based on system identification method[J].Journal of Dalian Maritime University,2008,34(4):67-71 